\title{
STARK WIDTH MEASUREMENTS OF NEUTRAL ARGON LINES AND COMPARISON WITH ANALOGOUS TRANSITIONS FOR HOMOLOGOUS ATOMS
}

\begin{abstract}
J. Musielok
Institute of Physics, Pedagogical University of Opole, Oleska 48, 45-052 Opole, Poland (Reccived March 11, 1994; in final form May 17, 1994)

Ifalf widths of 24 ArI lines from a wide interval of the spectrum and from a large range of excitation energies were measured. A wall-stabilized arc at atmospheric pressure was applied as a plasma generator. Electron densities of the plasma of the order of $10^{16}-10^{17} \mathrm{~cm}^{-3}$ were obtained on the basis of liydrogen $\Pi_{\beta}$ line broadening measurements. The measured widths of ArI lines, normalized to an clectron density of $10^{16} \mathrm{~cm}^{-3}$ were compared with experimental data for analogous transitions in other noble atoms.
\end{abstract}

PACS numbers: 32.70.-n, 32.70.J $2,52.25 . \mathrm{Rv}$

\section{Introduction}

Experimental contributions toward understanding of the Stark broadening in noble gases have largely focused on helium, neon and the most economical inert gas - argon. The knowledge of the Stark broadening parameters is essential e.g. for diagnostic purposes, because from the Stark width of a spectral line the electron density of the plasma can be easily deduced. The purpose of this paper is (i) to investigate the Stark broadening of ArI lines (from the visible to near infrared) and consequently from a wide interval of excitation energies (13.3-15.3 eV) and (ii) to compare the measured widths for argon lines with those for analogous transitions in other homologous emitters as neon, krypton and xenon.

\section{Experimental}

A wall-stabilized arc of the Maecker-Shumaker type [1, 2] at atmospheric pressure was used for generation of the plasma. By changing the arc current and selecting the gas composition $\left(\mathrm{Ar}+\mathrm{II}_{2}, \mathrm{Ar}+\mathrm{IIc}+\mathrm{II}_{2}, \mathrm{Ar}+\mathrm{N}_{2}+\mathrm{II}_{2}\right)$, plasmas of electron densitics near the arc axis in the range of $1.4 \times 10^{16}$ to $1.2 \times 10^{17} \mathrm{~cm}^{-3}$ and 
of temperatures between 9800 and $13400 \mathrm{~K}$, were produced (total number of experiments - 9). The radiation emitted in end-on direction, from the lomogeneous plasma volume around the arc axis, was analyzed applying a PGS2 spectrometer, equipped with a photomultiplicr. In a few cases a photographical detection of the spectrum was applied.

In the case of photoelectrical detection, the spectral line shapes were measured directly by turning the grating and measuring the photomultiplier output. In a few cases of photographical detection, the measured light transmissions of the photoplate were converted into the intensity scale via the characteristic curve of the photoplate for the given wavelengths.

A low current carbon arc after Euler $[3,4]$ and/or a calibrated tungsten strip lamp were used as radiation standards. For the purpose of line broadening measurements the knowledge of absolute line intensities was not critical at all. Ilowever, the measured intensities of the studied lines in their centres were applied for controlling the possible presence of sclf-alssorption of radiation in the homogeneous plasma layer. For all lines under study, the intensity in the line core was far below the blackbody limit for the corresponding wavelength and plasma temperature, indicating optically thin conditions. The clectron densities were obtained from the broadening of the $\mathrm{II}_{\beta}$ line, applying the data of Kepple and Griem $[5,6]$. In the electron density range of this paper, a simplificd formula for $N_{\mathrm{e}}$ determination can be used [7]:

$$
N_{\mathrm{e}}=1.01 \times 10^{16}\left(\Delta \lambda_{1 / 2}\right)^{1.45} \text {, }
$$

where $N_{\mathrm{e}}$ is obtained in $\mathrm{cm}^{-3}$ and $\Delta \lambda_{1 / 2}$ is the full width at half maximum (FWIIM) of the $\mathrm{H}_{\beta}$ line (in $\mathrm{nm}$ ).

The temperatures of the plasma were determined on the basis of measured total line intensities (in absolute units) of spectral transitions of neutral elements contained in the plasma (c.g. ArI, NI and III or ArI and III) and assuming that the plasma is in local thermal equilibrium at a total pressure of $1 \mathrm{~atm}$. In the case of the $\mathrm{Ar}+\mathrm{He}+\mathrm{II}$ plasma and for other "lighl temperature" experiments $(T>12000 \mathrm{~K})$ the Boltzmann plot method, based on ArII line intensity measurements, was applied.

The accurate knowlelge of the plasma temperature was not cssential at all for line broadening studies of $\mathrm{ArI}$ lines performed in this work. IIowever, the temperature values were used to estimate the small contributions from the Doppler broadening to the measured line widlhs. The pure Stark widths were evaluated after an appropriate "subtraction" of the Doppler as well as the apparatus broadening, from measured line widths.

\section{Results and data reduction}

In Table I the Stark widths (FWIIM) for 24 ArI lines from the wavelength interval $400-880 \mathrm{~nm}$, determined at different plasma conditions $\left(N_{\mathrm{e}}, T\right)$ are listed. The uncertainties of the evaluated Stark widtlis are mainly around $10 \%$. Only in the case of the lines $629.69,653.81,660.48,826.45$ and 852.14 the error may reach the level of $20 \%$. According to the theory [6], the FWIIM of a line caused by the 
TABLE I

Full (Stark) widths at half maximum for Arl lines (in pm) obtained at various plasma conditions.

\begin{tabular}{|c|c|c|c|c|c|c|c|c|c|}
\hline \multirow{3}{*}{$\begin{array}{c}\text { Wave- } \\
\text { length } \\
{[\mathrm{nm}]}\end{array}$} & \multicolumn{9}{|c|}{ Plasma paramelers: $N_{\mathrm{e}}$ in $10^{16} \mathrm{~cm}^{-3}, T$ in $\mathrm{K}$} \\
\hline & 12 & 9.9 & 8.5 & 5.1 & 4.5 & 4.2 & 3.1 & 2.9 & 1.4 \\
\hline & 13200 & 12600 & 12500 & 11500 & 13400 & 11300 & 10800 & 10750 & 9800 \\
\hline 404.44 & & & & 108 & 95 & & & & 30 \\
\hline 415.86 & & 200 & & 105 & 107 & & 60 & & \\
\hline 416.42 & & & & 96 & & & & & 30 \\
\hline 418.19 & & 245 & & 118 & 119 & & 75 & & 35 \\
\hline 419.10 & & 190 & & 103 & 117 & & 71 & & \\
\hline 420.07 & & & & & 94 & & & & \\
\hline 425.12 & & & & & & & 42 & & \\
\hline 425.94 & & 200 & & 114 & 108 & & 70 & & 31 \\
\hline 426.63 & & 240 & & 105 & & & 60 & & 33 \\
\hline 427.22 & & 180 & & 100 & 91. & & 50 & & 28 \\
\hline 430.01 & & 180 & & 105 & 90 & & 62 & & \\
\hline 433.36 & & & & & 110 & & & & \\
\hline 451.07 & & & & & 118 & & 73 & & \\
\hline 629.69 & & & & & & & & 730 & \\
\hline 630.77 & & & & & & & & 510 & \\
\hline 653.81 & & & & & & & & 300 & \\
\hline 660.48 & & & & & & & & 300 & \\
\hline 710.75 & & & & & & & & 320 & \\
\hline 712.58 & & & & & & & & 380 & \\
\hline 714.70 & 70 & & & & & & & & \\
\hline 720.70 & & & 1470 & & & 660 & & 400 & \\
\hline 826.45 & & & & & & 38 & & & \\
\hline 852.14 & & & & & & 31 & & & \\
\hline 876.17 & & & 1180 & & & 600 & & & \\
\hline
\end{tabular}

Strk broadening at an electron density of $10^{16} \mathrm{~cm}^{-3}$ can be calculated from the tormula

$$
\text { FWIIM }=2 w_{\lambda}[1+1.75 a(1-C r)],
$$

where $C=0.75$ for an atomic line and $C=1.2$ for an ionic one, $r$ is the so-called screening parameter, depending on electron density and temperature of the plasma, $w_{\lambda}$ is the electronic broadening parameter, depending mainly on the distance of the levels under consideration to the ncighbouring (perturbing) levels, $\alpha$ is the so-called ionic broadening parameter, contributing to the line width and causing 
an asymmetry of the line profile. The parameter $w_{\lambda}$ is proportional to the electron density $\left(N_{\mathrm{e}}\right)$, while the parameter $\alpha$ is proportional to $N_{\mathrm{e}}^{0.25}$.

In order to compare the results for a given line at different plasma conditions, and to compare our results with literature data, the measured line widths were normalized to an electron density standard value of $N_{\mathrm{e}}=10^{16} \mathrm{~cm}^{-3}$. Within the normalization procedure the temperature dependencies of $w_{\lambda}(T)$ and $\alpha(T)$ were neglected. Also the wcak dependence of $\alpha$ on electron density $\left(N_{\mathrm{e}}^{0.25}\right)$ and the very

TABLE II Comparison of normalized (to $N_{\mathrm{e}}=10^{16} \mathrm{~cm}^{-3}$ ) Stark widths of Ar I lines obtained in this work with experimental data taken from the literature and with calculated on the basis of theoretical broadening parameters taken from Griem [6].

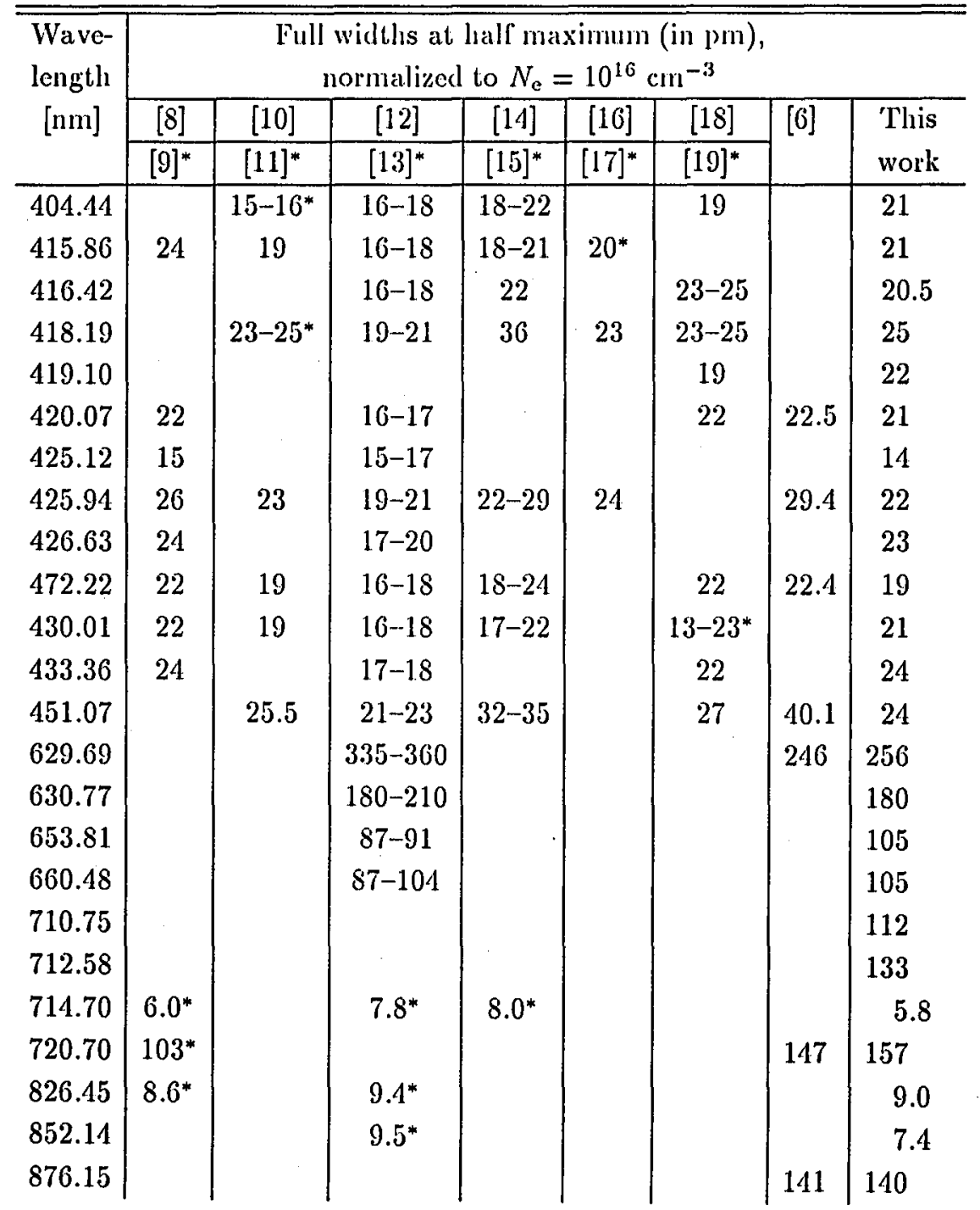


weak dependence of the screening parameter on $N_{\mathrm{e}}^{1 / 6}$ and $T^{-1 / 2}$ was neglected. In the range of the plasma parametcrs of this work, all those factors may influence the normalized widths by few percent only. In Table II these normalized FWIIM are compared with the data taken from the literature and calculated according to Griem [6].

TABLE III Full widtlis at half maximum of the studied ArI lines in frequency units (rad/s) normalized to an electron density of $10^{16} \mathrm{~cm}^{-3}$.

\begin{tabular}{c|c|c|c|c|c}
\hline \hline $\begin{array}{c}\text { Wave- } \\
\text { length } \\
\text { [nm] }\end{array}$ & Transition & $J_{m}-J_{n}$ & $\begin{array}{c}\text { Excitation } \\
\text { encrgies } \\
\left(E_{m}-E_{n}\right)[\mathrm{cV}]\end{array}$ & $\begin{array}{c}\left(\chi-E_{n}\right)^{-1} \\
{\left[\mathrm{eV}^{-1}\right]}\end{array}$ & $\begin{array}{c}\Delta \omega_{1 / 2} \\
{\left[10^{21}\right.} \\
\mathrm{rad} / \mathrm{s}]\end{array}$ \\
\hline 714.70 & $4 s[3 / 2]-4 p^{\prime}[3 / 2]$ & $2-1$ & $11.55-13.28$ & 0.377 & 0.21 \\
852.14 & $4 s^{\prime}[1 / 2]-4 p^{\prime}[3 / 2]$ & $1-1$ & $11.83-13.28$ & 0.377 & 0.22 \\
\hline 826.45 & $4 s^{\prime}[1 / 2]-4 p^{\prime}[1 / 2]$ & $1-1$ & $11.83-13.33$ & 0.384 & 0.29 \\
\hline 425.12 & $4 s[3 / 2]-5 p[1 / 2]$ & $2-1$ & $11.55-14.46$ & 0.772 & 1.5 \\
\hline 420.07 & $4 s[3 / 2]-5 p[5 / 2]$ & $2-3$ & $11.55-14.50$ & 0.797 & 2.2 \\
\hline 430.01 & $4 s[3 / 2]-5 p[5 / 2]$ & $1-2$ & $11.62-14.51$ & 0.803 & 2.0 \\
\hline 416.42 & $4 s[3 / 2]-5 p[3 / 2]$ & $2-1$ & $11.55-14.52$ & 0.810 & 2.2 \\
427.22 & $4 s[3 / 2]-5 p[3 / 2]$ & $1-1$ & $11.62-14.52$ & 0.810 & 1.95 \\
\hline 415.86 & $4 s[3 / 2]-5 p[3 / 2]$ & $2-2$ & $11.55-14.53$ & 0.816 & 2.3 \\
426.63 & $4 s[3 / 2]-5 p[3 / 2]$ & $1-2$ & $11.62-14.53$ & 0.816 & 2.4 \\
\hline 451.07 & $4 s^{\prime}[1 / 2]-5 p[1 / 2]$ & $1-0$ & $11.83-14.58$ & 0.851 & 2.2 \\
\hline 419.10 & $4 s^{\prime}[1 / 2]-5 p^{\prime}[3 / 2]$ & $0-1$ & $11.72-14.66$ & 0.786 & 2.35 \\
\hline 418.19 & $4 s^{\prime}[1 / 2]-5 p^{\prime}[1 / 2]$ & $0-1$ & $11.72-14.69$ & 0.805 & 2.7 \\
\hline 404.14 & $4 s[3 / 2]-5 p^{\prime}[3 / 2]$ & $1-2$ & $11.62-14.69$ & 0.805 & 2.5 \\
433.36 & $4 s^{\prime}[1 / 2]-5 p^{\prime}[3 / 2]$ & $1-2$ & $11.83-14.69$ & 0.805 & 2.3 \\
\hline 425.94 & $4 s^{\prime}[1 / 2]-5 p^{\prime}[1 / 2]$ & $1-0$ & $11.83-14.74$ & 0.839 & 2.3 \\
\hline 876.15 & $4 p^{\prime}[1 / 2]-4 d[3 / 2]$ & $1-2$ & $13.33-14.74$ & 0.985 & 3.4 \\
\hline 710.75 & $4 p[5 / 2]-6 s[3 / 2]$ & $2-2$ & $13.09-14.84$ & 1.09 & 4.2 \\
\hline 653.81 & $4 p[5 / 2]-4 d^{\prime}[3 / 2]$ & $3-2$ & $13.08-14.95$ & 1.02 & 4.6 \\
\hline 660.48 & $4 p[5 / 2]-4 d^{\prime}[3 / 2]$ & $2-3$ & $13.09-14.97$ & 1.04 & 4.5 \\
\hline 712.58 & $4 p^{\prime}[3 / 2]-6 s^{\prime}[1 / 2]$ & $1-1$ & $13.28-15.02$ & 1.10 & 5.0 \\
720.70 & $4 p^{\prime}[3 / 2]-6 s^{\prime}[1 / 2]$ & $2-1$ & $13.30-15.02$ & 1.10 & 5.7 \\
\hline 630.77 & $4 p[3 / 2]-5 d[3 / 2]$ & $2-2$ & $13.17-15.14$ & 1.63 & 8.5 \\
\hline 629.69 & $4 p^{\prime}[1 / 2]-5 d^{\prime}[3 / 2]$ & $1-2$ & $13.33-15.30$ & 1.58 & 12.0 \\
& & & &
\end{tabular}


In Table III the studied lines are listed in an order, determined by the excitation energy of the upper level $\left(E_{n}\right)$ of the corresponding transition. In the 5 th column the quantity $\left(\chi-E_{n}\right)^{-1}$ in $\mathrm{eV}^{-1}$ is listed, where $\chi$ is the energy limit of the specific ArI level system: $15.76 \mathrm{eV}$ and $15.94 \mathrm{eV}$ for the two systems under consideration, respectively. In the last column the corresponding line widths are listed in $\omega$ units (rad/s), evaluated according to the formula

$$
\Delta \omega_{1 / 2}=2 \pi c \lambda^{-2} \Delta \lambda_{1 / 2} \text {. }
$$

In Fig. 1 these widths (in frequency units) are plotted as a function of the reciprocal binding energy $\left(\chi-E_{n}\right)^{-1}$. The full circles and solid line represent the

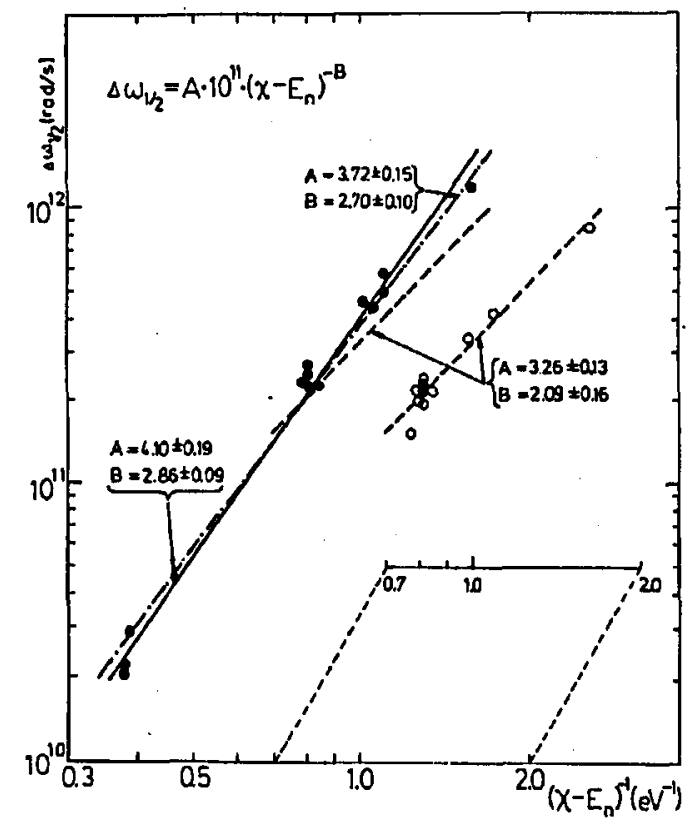

Fig. 1. The expcrimental Stark FWIIM (in frequency units) of ArI lines, normalized to an electron density value of $10^{16} \mathrm{~cm}^{-3}$, versus the reciprocal binding energy of the upper levels from which the emission lines originate. The full circles and the solid line correspond to spectral lines arising from primed upper levels, while the open circles and the dashed line correspond to the spectral lines arising from non-primed upper levels. The dotted-dashed line represents the best fit, when results for all studied lines are approximated by a formula of the type $\Delta \omega_{1 / 2}=A\left(\chi-E_{n}\right)^{-B}$.

results for lines originating from primed upper levels, while the open circles and the dashed line represent the results for lines with non-primed upper levels. The results of both line groups (level systems) are well fitted by formulas of the type, proposed by Puric et al. [20]:

$$
\Delta \omega_{1 / 2}=A\left(\chi-E_{n}\right)^{-B} \text {. }
$$

The corresponding values for $A$ and $B$ are quoted in the figure. If both groups of 
lines (both level systems) arc taken together, a best fit for $A=(3.72 \pm 0.15) \times 10^{11}$ and $B=2.70 \pm 0.10$ is obtained (dashed-dotted line).

As one can see, the formulas can be used with confidence for estimation of the widths for ArI spectral lines with unknown broadening parametcrs.

\section{Comparison of results obtained for argon with literature data for homologous atoms}

The experimental data of this work support the well-known fact that in most cases the main contribution to the Stark width of a spectral line arises from the broadening of the upper level of the respective transition. Indeed, the normalized Stark widths determined in this work scalc, as expccted, with the upper level ionization energy according to Eq. (4). The width of the upper level itself is determined by its "interaction" with neighbouring perturbing levels [6]. Because of similarities of the energy level system of inert gases, one can also expect some regular behaviour of the Stark broadening parameters for analogous transition, along the atomic number of noble emitters. Recently, such regularities have been reported e.g. by Di Rocco [31] and Bertuccelli and Di Rocco [32] for singly ionized inert gases and Djeniže et al. for singly ionized elcments of the second group in the periodic system [33].

Therefore, our results for argon are compared with data available in the literature for Ne, Krr and Xe. Unfortunately, for only 13 of the studied Ar lines, data for analogous transitions in other noble gases could be found: 6 for Nel (Refs. [21-23] and [29]), 3 for Krrl (Refs. [24, 27] and [28]), and 7 for XeI (Refs. [24-26] and [30]).

In Table IV the FWIIM (in frequency units), normalized to a common electron density value of $10^{16} \mathrm{~cm}^{-3}$, originating from homologous upper levels of $\mathrm{Ne}$, $\mathrm{Ar}, \mathrm{Kr}$ and $\mathrm{Xe}$ and the corresponding ionization energics are listed. In Table $\mathrm{V}$ similar data for the remaining analogous transitions in $\mathrm{Ar}, \mathrm{Kr}$ and $\mathrm{Xe}$ are presented. As one can sce, for almost all these transitions a clear tendency could be revealed: the normalized line width (in frequency units) increases with decreasing ionization energy of the upper level of the transition under consideration. Only the results obtained by Purić et al. [21] for Nel do not follow this rule. These line broadening data are systcmatically too large, not only compared with our results for ArI, but also compared with other experimental data obtained by Nubbemeyer et al. [23] and Döhın and IIclbig [29].

Unfortunately, only for the transition array $n s-n p^{\prime}(n=3$ for $\mathrm{Ne}, n=4$ for Ar etc.) results for all 4 elements ( $N e, A r$, Kír and Xe) are available. For neon and argon, additional results for the transition $n s^{\prime}-n p^{\prime}$ are reported. These results for 4 NeI lines, 3 ArI lincs and one for KrI and XeI are compared in Table IV. All these lines originate from common upper levels $n p^{\prime}[1 / 2]_{1}$ or $n p^{\prime}[3 / 2]_{1}$. As can be seen, with increasing atomic number $(Z)$ the bond energy (or ionization energy) of the upper level $n p^{\prime}$ decreases systcmatically from $2.97 \mathrm{eV}$ for $\mathrm{Ne}$ to $2.39 \mathrm{eV}$ for Xe.

In Fig. 2 two quantities, as a function of the inverse ionization energy of the upper level, are plotted: 
1. below the solid border line connecting the element symbols - the normalized FWIIM $\Delta \omega_{1 / 2}$ in frequency units, and

2. above the solid line - the same widths $\left(\Delta \omega_{1 / 2}\right)$ multiplied by $Z^{1 / 2}$, where $Z$ is the atomic number of the emitter.

The second quantity is a particular form of a more general expression $Z^{l>/ 2}$, which has been found to fit very well the data obtained for singly ionized noble atoms [32]. The symbol $l>$ in the exponent is the greater orbital quantum number of the studied transition - in our case for the transition $s\left(s^{\prime}\right)-p^{\prime}, l>=1$.

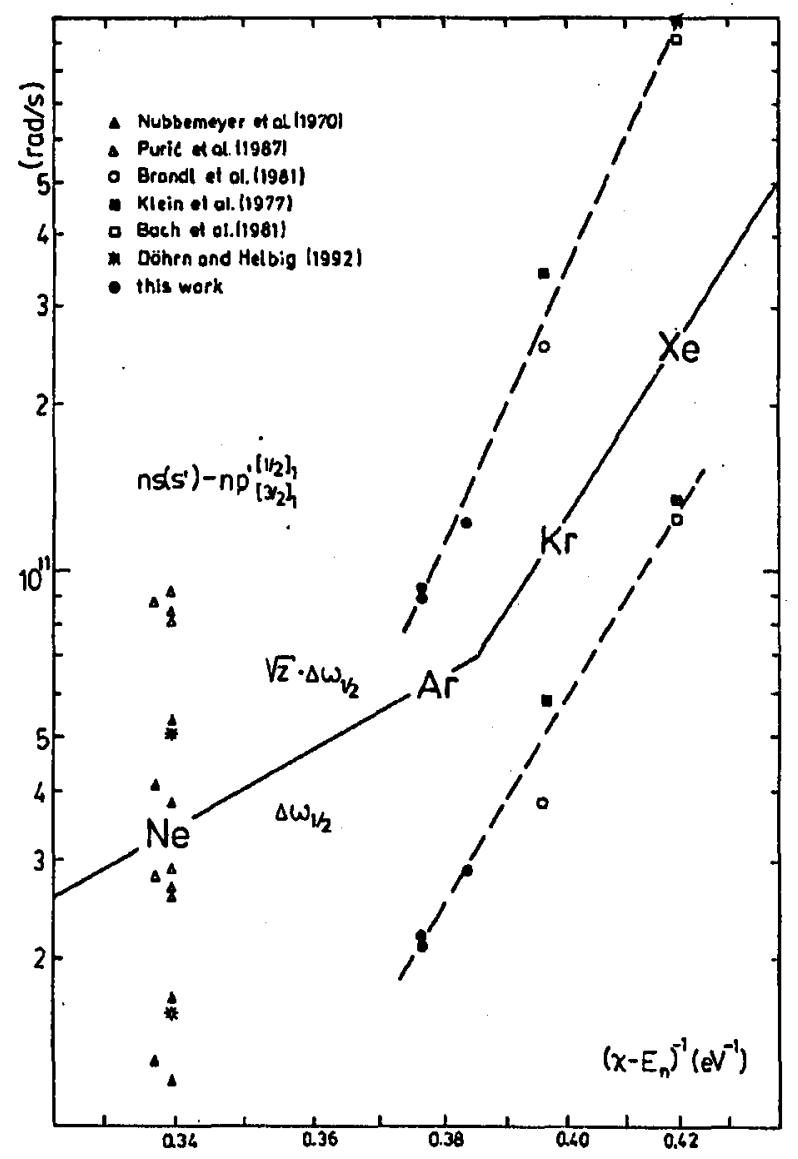

Fig. 2. Comparison of broadening data for spectral lines of noble gases. Two quantities as a function of the inverse ionization energy of the upper level are shown: (1) below the solid line connecting the element symbols - the normalized FWIIM $\Delta \omega_{1 / 2}$, and (2) above the solid line - the same widths multiplied by the square root of the atomic number of the emitter. 
TABLE IV

Full widths at half maximum (in frequency units) normalized to an electron density of $N_{\mathrm{c}}=10^{16} \mathrm{~cm}^{-3}$ for spectral lines of Ar, Kir and Xc, originating from homologous upper levels, characterized by their individual ionization energies $I_{n}$ in $\mathrm{cV}$.

\begin{tabular}{|c|c|c|c|c|c|}
\hline \multirow{2}{*}{ Element } & \multirow{2}{*}{$\begin{array}{l}\text { Binding } \\
\text { cnergy } \\
I_{n} / \mathrm{eV}\end{array}$} & \multicolumn{4}{|c|}{ Designation of the upper level } \\
\hline & & $4 p^{\prime}[3 / 2]_{1}$ & $4 p^{\prime}[1 / 2]_{1}$ & $4 d[3 / 2]_{2}$ & $6 s^{\prime}[1 / 2]_{1}$ \\
\hline $\mathrm{Ne}$ & $\begin{array}{l}2.97 \\
2.94 \\
\\
\\
1.52 \\
1.00\end{array}$ & $\begin{array}{l}0.28^{a} \\
0.13^{c}\end{array}$ & $\begin{array}{l}0.26^{a} \\
0.27^{a} \\
0.29^{a} \\
0.17^{c} \\
0.12^{c} \\
0.16^{i}\end{array}$ & $1.4^{a}$ & $3.3^{b}$ \\
\hline Ar & $\begin{array}{l}2.65 \\
2.60 \\
1.02 \\
0.91\end{array}$ & $\begin{array}{l}0.21 \\
0.22\end{array}$ & 0.29 & 3.4 & $\begin{array}{l}5.7 \\
5.0\end{array}$ \\
\hline Kr $\mathbf{r}$ & 2.52 & & $\begin{array}{l}0.58^{d} \\
0.39^{g}\end{array}$ & & \\
\hline $\mathrm{Xe}$ & 2.39 & & $\begin{array}{l}1.30^{\mathrm{d}} \\
1.25^{e}\end{array}$ & & \\
\hline
\end{tabular}

As can be seen, the results for $\Lambda \mathrm{r}$, Kr and $\mathrm{Xc}$ are well fitted by the formula $\Delta \omega_{1 / 2}=A_{1} I^{-B_{1}}$ as well as by the relation $Z^{1 / 2} \Delta \omega_{1 / 2}=A_{2} I^{-B_{2}}$.

Only the widths reported for NeI lines do not fit the "regularity trends". The results for Ne I obtained by Puric et al. [21] are approximatcly 2 times larger than the "old" data of Nubbemeycr et al. [23]. These "old" data seems to be much more reliable and liave been recently confirmed in the experiment of Döhrn and IIelbig [29]. Even ignoring the results of Puric et al., the deviation of the Ne data from the regularity trends for homologous atoms is very large. 
TABLE V

Full widths at half maximum (in frequency units) normalized to an electron density of $N_{\mathrm{e}}=10^{16} \mathrm{~cm}^{-3}$ for spectral lines of $\mathrm{Ar}$, Kr and $\mathrm{Xe}$, originating from homologous upper levels, characterized by their individual ionization energies $I_{n}$ in $\mathrm{cV}$.

\begin{tabular}{|c|c|c|c|c|c|c|}
\hline \multirow{2}{*}{ Element } & \multirow{2}{*}{$\begin{array}{c}\text { Binding } \\
\text { energy } \\
I_{n} / \mathrm{eV}\end{array}$} & \multicolumn{5}{|c|}{ Designation of the upper level } \\
\hline & & $5 p[1 / 2]_{0}$ & $5 p[3 / 2]_{2}$ & $5 p[3 / 2]_{1}$ & $5 p[5 / 2]_{2}$ & $5 p[5 / 2]_{3}$ \\
\hline \multirow{7}{*}{ Ar } & 1.18 & 2.2 & & \multirow{7}{*}{$\begin{array}{l}2.2 \\
1.95\end{array}$} & \multirow{7}{*}{2.0} & \\
\hline & 1.22 & & 2.3 & & & \\
\hline & & 2.4 & & & & \\
\hline & 1.23 & & & & & \\
\hline & & & & & & \\
\hline & 1.24 & & & & & \\
\hline & 1.25 & & & & & 2.2 \\
\hline \multirow{3}{*}{$\mathbf{K} \mathbf{r}$} & 1.14 & $4.1^{d}$ & \multirow{3}{*}{$3.0^{d}$} & & & \\
\hline & 1.22 & & & & & \\
\hline & & & & $2.7^{h}$ & & \\
\hline \multirow{10}{*}{$\mathrm{Xe}$} & 1.12 & $3.1^{e}$ & \multirow{10}{*}{$\begin{array}{l}5.9^{e} \\
5.5^{e} \\
7.2^{d} \\
6.7^{j}\end{array}$} & & & \multirow{10}{*}{$\begin{array}{l}4.8^{e} \\
5.8^{d} \\
5.6^{j}\end{array}$} \\
\hline & 1.13 & & & $3.85^{d}$ & & \\
\hline & 1.14 & & & & & \\
\hline & & & & & & \\
\hline & & & & & & \\
\hline & \multirow{4}{*}{1.16} & & & & & \\
\hline & & & & & & \\
\hline & & & & & & \\
\hline & & & & & & \\
\hline & 1.18 & & & $\begin{array}{l}4.8^{f} \\
4.7^{e}\end{array}$ & & \\
\hline of & 1305 & & & $\frac{1.11}{81}$ & & \\
\hline
\end{tabular}

This departure of results for neon from the regularity rule can be explained on the basis of detailed analysis of regularitics of the energy level system in noble gases [34]. Indeed, the encrgy levels responsible for the emission of the studied lines and the levels which "interact" with the levels of interest of $\mathrm{Ar}, \mathrm{Kr}$ and $\mathrm{Xe}$ show clear regular trends, while the corresponding $\mathrm{Ne}$ levels reveal distinct dissimilarities. 


\section{Conclusions}

Line broadening parameters (the Stark widllis) for an extensive set of ArI lines determined in this work verify the characteristical dependencies of the Stark widths on the upper level ionization energy. This regularity observed in ArI spectrum can be used for estimation of the Stark broadening parameters of lines, for which no data are reported in the literature. Comparison of results obtained for ArI with data for analogous transitions in other noble gases, reveals typical regularity of the Stark width dependence on the upper level ionization energy in the sequence of atoms Ar-Kr-Xe. Deviations from the regular trend for Ne lines were found, which can be attributed to some peculiarities of the encrgy level system of neon.

\section{References}

[1] II. Maecker, Z. Angew. Phys. 15, 140 (1963).

[2] J.B. Slumaker, Rev. Sci. Instrum. 32, 65 (1960).

[3] J. Euler, Ann. Phys. 11, 202 (1953).

[4] M.R. Null, W.W. Lozier, J. Opt. Soc. Am. 52, 1156 (1962).

[5] P.C. Kepple, Rep. 831, University of Maryland, 1968.

[6] H.R. Griem, Spectral Line Broadening by Plasmas, Academic Press, New York 1974.

[7] J. Musiclok, Stark Broadening of Speclral Lines and ils Applicalion in Plasma Diagnostics, Studia i Monografie, Nr 177, WSP, Opole 1991 (in Polish).

[8] W.E. Gericke, Z. Astrophys. 53, 68 (1961).

[9] V. Baksli, R.J. Kearncy, J. Quant. Spectrosc. Radiat. Transf. 42, 105 (1989).

[10] D.W. Jones, W.L. Wiese, L.A. Wolt\%, Phys. Rev. A 34, 450 (1986).

[11] P. Schulz, B. Wenle, Z. Pliys. 208, 116 (1968).

[12] I. Bues, T. Haag, J. Richter, Laboratoriumsbericht, Universität Kicl, Kiel 1969.

[13] D.W. Jones, K. Musiol, W.L. Wiese, in: Speclral Line Shapes, Vol. 2, W. de Gruyter, Berlin 1983, p. 125.

[14] B. Musiclok, J. Musiclok, T. Wujcc, Zcsz. Nauk. WSP w Opolu Fiz. 17, 63 (1976).

[15] A.M. Tonejć, K. Acinger, V. Vujnović, J. Quant. Spectrosc. Radiat. Transf. 12, 1305 (1984).

[16] P. Klein, D. Meincrs, J. Quant. Spectrosc. Radiat. Transf. 17, 197 (1977).

[17] D.W. Jones, G. Pichler, W.L. Wicse, Phys. Rev. A 35, 2585 (1987).

[18] J. Chapelle, Sy. Cabonne, F. Cabannes, J. Blandin, J. Quant. Spectrosc. Radiat. Transf. 8, 1201 (1967).

[19] J.L. Queffelec, M. Girault, Rev. Phys. Appl. 6, 401 (1971).

[20] J. Purić, M. Ćuk, I.S. Lakićcvić, Phys. Rev. A 32, 1106 (1985).

[21] J. Purić, M. Ćuk, B.A. Rathore, Phys. Rev. A 35, 1132 (1987).

[22] W. Schade, K.-P. Nick, V. IIelbig, in: Speclral Line Shapes, Vol. 3, Ed. F. Rostas; W. de Gruyter, Berlin 1985, p. 59.

[23] H. Nubbemeyer, D. Stuck, B. Wcnde, Z. Phys. 234, 29 (1970). 
[24] P. KRlein, D. Meiners, J. Quant. Spectrosc. Radiat. Transf. 17, 197 (1977).

[25] Truong-Bach, J. Richou, A. Lesage, Il.II. Miller, Phys. Rev. A 24, 2550 (1981).

[26] A. Lesage, J. Richou, J. Quant. Spectrosc. Radiat. Transf. 12, 1313 (1972).

[27] T. Brandt, V. Ilelbig, K.-P. Nick, in: Spectral Line Shapes, Vol. 1, Ed. B. Wende, W. de Gruyter, Berlin 1981, p. 265.

[28] P. Baessler, II.U. Obbarius, E. Schulz-Gulde, Physica C 93, 114 (1978).

[29] A. Döhrn, V. IIelbig, in: Spectral Line Shapes, Vol. 7, Eds. R. Stamm, B. Talin, Carry le Rouet 1992, p. A29.

[30] M. Kettlitz, R. Radtkc, R. Spanke, in: XVII Inlernat. Conf. on Plenomena in Ionized Gases, Budapest 1985, p. 999.

[31] H.O. Di Rocco, Appl. l'hys. 68, 3732 (1990).

[32] G. Bertuccelli, II.O. Di Rocco, Phys. Scr. 44, 138 (1991).

[33] S. Djeniže, A. Srećković, J. Jabat, J. Quant. Speclrosc. Radiat. Transf. 46, 433 (1991).

[34] S. Bashkin, J.O. Stoncr, Alomic Encrgy Levels and Grolrian Diagrams, North-Holland, Amster!an 1978. 